\title{
EFFECT OF MOTOR INSURANCE CLAIMS SETTLEMENT ON INSURANCE PENETRATION IN NIGERIA
}

Department of Insurance and Risk Management, Faculty of Management Sciences, Enugu State University of Science and Technology (ESUT), Enugu, Enugu State Nigeria

E-mail: Agbo.ishmael@yahoo.com

AGBAJI, Benjamin Chukwuma (Ph.D)

Department of Insurance and Risk Management, Faculty of Management Sciences, Enugu State University of Science and Technology (ESUT), Enugu, Enugu State Nigeria E-mail: agbajiben@gmail.com

\section{Abstract}

This study evaluated "the effect of motor insurance claims settlement on insurance penetration in Nigeria". The objective of the study is; to examine the effect of motor insurance claims settlement on insurance penetration in Nigeria. The study used secondary data from CBN statistical bulletin 2017. The technique used for analysis was the ordinary least squares which were employed to test the hypothesis. The study concluded that motor insurance claims settlement have a positive effect on insurance penetration in Nigeria. This study recommends that for the safety of injured third parties and damage to property caused by motor accident, insurance should improve their use of modern day technology in facilitating motor insurance claims settlement.

Keywords: Motor Insurance, Claims Settlement, Insurance Penetration.
\end{abstract}

\section{Introduction}

The term of insurance means a firm financial loss protection; it is basically used to protect a firm from risk arising from uncertain loss. This service is usually provided by insurance company which is also known as an insurer, insurance carrier or underwriter. An insured or a policyholder is known as an entity who buys insurance. The insured assume a guaranteed during insurance transaction, he is aware of little loss in the payment made to the insurer which the insurer offer the insured compensation promise in case there is any event of a covered loss. Better put, the insured takes responsibility for the occurrence of risk in the part of insurer when he made payment to the insured for a period of time. The loss may be financial or non- financial, but it must be factored to financial terms which normally includes things the insured has an insurable interest recognized by ownership, possession, or preexisting relationship. The contract the insured receive is known as insurance policy, its specifics the circumstances and the conditions which the insurer is meant to recompense the insured.

Premium is the amount of money which the insured charge the insurer for the coverage set forth in the insurance policy. The insured submits a claim to the insurer for processing by a claims adjuster, if the insured experiences a loss which is potentially covered by the insurance policy. If the primary insurer deems the risk too large for it to carry, he can contact another insurance company who will agree to carry some of the risk. The insurer is at liberty to limit its own risk by taking out reinsurance. There are various types of insurance policies in Nigeria, but this study seeks to focus on motor insurance policy. 
Motor can as well be called vehicle insurance; cars, bike, truck, etc. adopt this type of insurance policy. Vehicle uses it against unforeseen natural catastrophe. Basically, there are two types of vehicle insurance policies namely; comprehensive and third party insurance cover or plan.

It's seems confusing sometimes in making vehicle insurance plan choice. Your choice of this vehicle insurance is base of having the understanding the benefit and features or under taking an in depth study of the plans available for easy adoption of your choice insurance plans. Third party; this type is a type of insurance policy which covers those damages that affects the third party by the person. Better put, in event of accident, the insurer insurance plan is limited to the damages cause to the third party car and its related accessories by him. It also provides coverage for injuries done to the third party during the accident. It account for the third party liability, not on yours. Whereas comprehensive insurance plans as the name implies covers all damages done to your vehicle and also covers the damages done to the third party.

In principle, the key functions of insurance plan is to compensation or indemnify and restore the insured to his/her economic and financial position prior to the occurrence of the event as a result of an insurance purchase. An insured purchase is just a promise from the insurer to make a payment claim arising after the purchase and consistent with the policy sold. The materialized utility of insurance is claim and loss handling, which depicts the actual "protect" paid for.

An insurance claim is an official request presented to the insurance company demanding payment as per the policy terms. This payment is in line with insurance policy. Simply put, an insurance claim is a notification to an insurance company requesting payment of an amount due under the terms of the policy; a request for reimbursement from the insurance company when the insured has suffered a loss that is covered under an insurance policy.

When an insured applies for claims, he/she should notice the rules and procedures that guide such. On the other hand, the insurer has to respond in a similar manner by undertaking suitable steps for speedy disposal of claims. Agu (1999) observed that despite that claim settlement is complex in nature; it is the driving force to plant confidence in the heart of people, in general and beneficiaries in specific: Dispute comes up when the insurer and insured understand the process of claims payment in different ways. For any insurance company, sales of insurance policies are major source of revenue and their prime motive for business. Since today business activities are interconnected, services related to claim settlement have impact on sales of insurance policies to great extent.

Therefore, a negative or positive approach towards the settlement of insurance claims, will determine the sales and turnover of insurance firms. Thus, this study seeks to examine the effect of motor insurance claims settlement on insurance penetration in Nigeria.

\section{Statement of the Problem}

One primary factor that influences the choice of insurance firm's customers is the claims settlement practice of an insurer. Invariably, the claims settlement practice of these insurance firms affects the level of insurance penetration in the country.

In Nigeria, there have been recent arguments and controversies on whether insurance firm's claims settlement practices significantly affect the purchase of motor insurance policy by car owners, the government, private owners and commercial drivers; thus the necessitation for this study.

\section{Objectives of the Study}

The broad objective of the study is; to examine the effect of motor insurance claims settlement on insurance penetration in Nigeria. The specific objective of this study is: 
1. To examine the effect of motor insurance claims settlement on insurance penetration in Nigeria.

\section{Literature Review \\ Concept of Insurance}

The concept of insurance entails the process by which an insured shift risk of loss to another party called insurer on the payment of premium as charge to the insured. However, insurer represents the insurance company or an organization which its duties are to share the loss and again it is qualify to do so. Insurance is a contractual relationship between two person i.e. the insurer and insured, the insurer agrees to pay a fixed amount in exchange for a fixed sum called premium, on the occurrence of a particular event like at a certain age or on death, the actual loss is also compensated when it occurs, a moment the risk is insured.

\section{Concept of Claim Settlement}

Marquis (2011) asserts that claim settlement consists of the departmental stipulation, corporate policies and practices made by industry which insurance companies adopt to authenticate reimbursement request and policyholder payment, Gallagher (2012) posits that claims arising from loss events should be supervise and control by an appropriate insurance organizational authorities, this is own view of claims settlement. Claims handling simply means an opportunity which insurance company deem it feet to fulfill the promises made to indemnify their customers for a valid claims and also a truthful time to the insurance company. Kapoor (2008) posits that the core purpose and application of claim settlement is to raise the insurance promise benefit, all terms and condition of the insurance policy are provided and met which the insured has acted with due diligence, if not insured his asset is subject to dangers (Peverett, 1993). The key objectives of claims management as asserted by Redja (2008), seek to authenticate that a covered loss has happened for prompt settlement of claims and to the insured.

\section{Concept of Motor Insurance}

Oyetayo (2006) defined motor insurance contract as an agreement between one party (the insurer) and another (the insured) whereby the insurer in consideration for the settlement of a definite sum (the premium) by the insured, the insurer agrees to pay back the insured in respect of the loss and or liability arising from the use of the insured vehicle(s) (the subject matter of insurance) on the road as defined.

Motor insurance is insurance covers cars, trucks, bikes and other road vehicles. Its primary made to cover all losses done to vehicles resulting from traffic collision and against liability which can also arise. It is the insurance purchase by vehicles owner to cover against losses emerging due to traffic accidents, or theft.

It covers physical damage which affect your vehicle any other vehicle you might come in contact with. Motor insurance also offers liability protection. What this means is if you have an accident and another person is injured, you vehicle insurance policy cover a portion of their medical expenses. Liability car insurance can also offer protection against property damage.

Motor or vehicle insurance, seems to be the most commonly known insurance policy used or adopted by people which is structured to protect the insured against damage to his vehicle, third party property damage including injured body and third party death caused by accident. Motor insurance is designed to provide cover against losses and liabilities that the driver may suffer in occurrence of an accident, theft or certain other events relating to their vehicle. It 
covers financial indemnity liability for any injuries caused by the driver or owner of motor cars to other people or their property.

Motor insurance also covers the policyholder financial loss against accident involving a vehicle they own, such as traffic collision.

Coverage typically includes:

- Property coverage, for damage to or theft of the car

- Liability coverage, for the lawful obligation to others for injured body or damage property, medical

- Medical coverage, for the cost of rehabilitation, treating injury and most at times funeral expenses and loss of wages

\section{Types of motor policies}

Once you buy motor vehicle you are expected to buy insurance policy. Though there are many of motor vehicle insurance policies, below are the most common ones namely;

- Third party covers: This policy covers you against claims bodily injuries or deaths caused third party as well as his property caused by your vehicle.

- Third party, fire and theft cover: this type covers against loss or damage done to third party property and also loss done to your vehicle cause by theft and fire.

- Comprehensive cover: this type covers extensively the damage done to thirty party properties and your own vehicle base on theft and fire or an accident.

\section{Important points to consider when buying motor insurance policies Insured value/sum insured}

Whenever you are purchasing a policy against loss/damage to your motor vehicle, do well to insured your vehicle adequately because it will affect your claims in occurrence of loss or damage. The insured value becomes the purchase price for a new vehicle while the market value becomes the insured value for other vehicles at the point you apply for insurance policy.

- Under-insurance - if your vehicle is insured at a lesser amount than what is sold in the market you will be deemed as self-insured for the difference, i.e. in the event of loss/damage, you will only be partially compensated (up to the proportion of insurance) by your insurance company.

- Over-insurance - Should you insure your vehicle at a higher sum than its market value, the maximum compensation you will receive is the market value of the vehicle as the policy owner cannot 'profit' from a motor insurance claim.

\section{Duty of disclosure}

You should disclose fully all material facts, including previous accidents (if any), adjustment to engines, etc. When in doubt as to whether a fact is appropriate or not, it is best to ask your insurance company. If you fail to release any material fact, your insurance company may refuse to pay your claim or any claim made by a third party against you. In such cases, you are personally accountable for such claims.

\section{Price}

The price you pay for your motor insurance will depend on the type of policy selected. The insurance premium charged by your insurance company is the standard minimum rate in agreement with the Motor Tariff. 
However, in addition to the normal minimum rate, your insurance company may levy supplementary premiums known as loadings to the premium payable in view of higher risk factors involved such as age of vehicle and claims experience. Loadings are governed by Bank Negara Malaysia (BNM) and no insurance company may charge loadings higher than the levels permitted by BNM.

\section{No-claim-discount}

The premium payable may be reduced if you have no-claim-discount (NCD) entitlement. NCD is a 'reward' scheme for you if no claim was made against your policy during the preceding 12 months of policy. Different NCD rates are appropriate for different classes of vehicles. For a private car, the scale of NCD ranges from $25 \%$ to $55 \%$ as provided in the policy.

\section{Excess}

Also known as a 'deductible': This is the amount of loss you have to bear before your insurance company will pay for the balance of your vehicle damage claim. The types of excess pertinent are as follows:

Obligatory excess of RM400 - if your vehicle is driven by a person not named in your policy or a person named in your policy that is under the age of 21 , the holder of a provisional (L) driving licence or the holder of a full driving licence of less than two years.

Other excess - appropriate at the discretion of your insurance company and in some cases, no excess is compulsory. You can transfer with your insurance company on this excess.

\section{Insurance policy}

With the application of e-cover note in 2005, insurance companies will transport motor insurance information electronically to the Road Transport Department (RTD) and you will receive validation slip containing details of your motor cover as validation of the purchase of your motor insurance. Thereafter, within one month, you should receive:

- the Timetable which shows your name and address, details of the vehicle, the sum insured (for complete and third party fire \& theft policies), the period of insurance, the policy number, your NCD right, premium breakdown, excess and named drivers;

- the certificate of insurance which shows your name, vehicle model, registration number and cubic capacity, period of insurance, authorized drivers and restrictions of use. In some cases, this may be issued at the point of purchase in place of the cover note; and

- a motor policy which shows the terms and conditions of cover provided by your insurance company.

If you do not receive your policy within one month, you should check with your insurance company

\section{What you should do in the event of an accident/loss}

- Take notes of the accident - If you are involved in a motor accident, take notes of the accident, i.e. the names and addresses of all drivers and passengers involved, vehicle registration numbers, make and model of each vehicle involved, the drivers' licence numbers and insurance proof of identity as well as the names and addresses of as many onlookers as possible

- Make a police report - You are required by law to lodge a police report within 24 hours of a road accident.

- Notify your insurance company - You must notify your insurance company in writing with full details as soon as possible. Depending on the type of claim you intend to make, you may have to notify other insurance companies (please refer to 'Making a claim against an 
insurance company' for details). If you fail to report the accident, you will be liable for your own loss as well as any third party claim against you.

- Select the workshop - You must send your damaged vehicle to a workshop approved by your insurance company. If the accident occurs during office hours, you may call the hotline/ emergency assistance numbers provided by your insurance company. Otherwise, you may call your insurance company for the nearest approved workshop.

\section{Making a Claim against an Insurance Company under Motor Insurance Policy}

When you are involved in an accident, you may either make an own damage claim or a third party claim:

\section{Own damage claim}

- This refers to making a claim on your own insurance policy, i.e. you have a comprehensive policy. However, you will lose your NCD entitlement.

- In notifying your insurance company of the accident, enquire about the names of approved workshops to send your vehicle for repair.

- Submit the fully completed Motor Accident Report Form together with all supporting documents as soon as possible to your insurance company.

- The workshop will commence repairs on your vehicle upon the approval of your insurance company. - Upon completion of repairs, you will be informed by the workshop to collect your vehicle.

\section{Third party claim}

- You may make a third party claim if you are not the party at fault in the accident and you can retain your NCD entitlement.

- There are two ways of making a third party claim, i.e. submit the claim directly to the insurance company of the party at fault or, if you have a wide-ranging policy, submit the claim to your insurance company. You are encouraged to submit your claim to your own insurance company for prompter claims processing.

- As the third party claimant, you are required to mitigate your loss i.e. you must act to minimize your loss.

- Appoint a licensed adjuster to assess the loss. The workshop or the third party insurance company may advise you on this.

- Submit the adjuster's report and the fully completed Motor Accident Report Form together with all supporting documents as soon as possible.

- You are eligible to claim from the third party insurance company for 'recompense for actual repair time' (CART) and reimbursement of excess. For the actual repair time of your vehicle, this is based on the adjuster's endorsement on the number of days required for your car to be repaired. Insurance companies, at their own discretion, may allow an additional seven working days for any unforeseen or inevitable delay.

\section{Research Methodology}

\section{Research Design}

The research adopted ex-post facto research design. The choice of the ex-post facto design is because the research relies on already recorded events, and researchers do not have control over the relevant dependent and independent variables they are studying with a view to manipulating them.

\section{Nature and Source of Data}

The study used secondary sources of information obtained from the CBN statistical bulletin, 2016. 


\section{Population of Study}

The population of study consists of the entire firms in the Nigerian insurance sector.

\section{Model of Study}

The model of study is based on simple linear regression, which is a statistical method that provides summary and study the relationship between two continuous (quantitative) variables: An econometric analysis of which insurance penetration is the dependent variable while the independent variable is total motor claim settlement.

\section{Description of Model Variables \\ Independent Variable}

Motor insurance claims payment: this refers to the total value of all the motor insurance claims paid for by the entire Nigerian insurance industry. It covers all the claims that the insurance industry paid to their motor insurance clients in a given business year. Therefore, the total motor insurance claims settlement was calculated as:

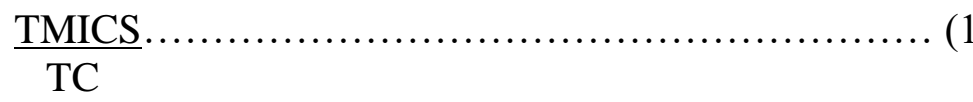

Where:

$\begin{array}{lll}\text { TMICS } & = & \text { Total Motor Insurance Claims Settlement } \\ \text { TC } & = & \text { Total Claims }\end{array}$

\section{Dependent Variable}

Insurance penetration: Generally, insurance penetration measures the contribution of insurance premium to Gross Domestic Product (GDP) of a country in percentage terms. Penetration rate indicates the level of development of insurance sector in a country. Penetration rate is measured as a ratio of premium underwritten in a particular year to the GDP. Insurance penetration was calculated as:

$$
\text { TPU.......... }
$$

Where:
TPU
$=$
Total Premium Underwritten
GDP
$=$
Gross Domestic Product

\section{Model Specification}

The model to be used in this study is:

\section{Hypothesis one}

Motor insurance claims settlement does not have positive effect on insurance penetration in

Nigeria. Therefore, hypothesis one is modeled as follows:

$$
\mathrm{IP}_{\mathrm{t}}=\beta_{\mathrm{o}}+\beta_{1} \mathrm{TMICS}_{\mathrm{t}}+\mu_{\mathrm{t}}
$$

Where:

$\begin{array}{lll}\operatorname{TMICS}_{\mathrm{t}} & = & \text { Total Motor Insurance Claims Settlement } \\ \mathrm{IP}_{\mathrm{t}} & = & \text { Insurance Penetration } \\ \mu_{\mathrm{t}} & = & \text { error } \\ \mathrm{t} & = & \text { time } \\ \beta_{\mathrm{o}} & = & \text { intercept of variable } \\ \beta_{1} & = & \text { Proxy of insurance penetration }\end{array}$




\section{Data Analysis Technique}

The ordinary least squares regression (OLS) was used as the data analysis technique. This is a method for estimating the unknown parameters in a linear regression model. The regression analysis was done with the aid of E-views version 9.

\section{Data Presentation and Analysis \\ Data presentation}

This study focused on the effect of fire insurance claims, motor insurance claims and marine insurance claims and marine insurance claims on insurance penetration in Nigeria from year 1995 to 2011.

Table 1: Data Presentation on Motor Insurance Claims and Insurance Penetration

\begin{tabular}{|l|l|l|}
\hline YEAR & $\begin{array}{l}\text { TMICS } \\
\mathbf{\%}\end{array}$ & $\begin{array}{l}\text { IP } \\
\mathbf{\%}\end{array}$ \\
\hline 1994 & 0.460097134 & 8.322877425 \\
\hline 1995 & 0.373550748 & 5.038561123 \\
\hline 1996 & 0.43065253 & 3.479782997 \\
\hline 1997 & 0.465567507 & 4.017622039 \\
\hline 1998 & 0.425754033 & 3.888975922 \\
\hline 1999 & 0.308055808 & 2.759159698 \\
\hline 2000 & 0.320496241 & 3.266620838 \\
\hline 2001 & 0.37900866 & 3.562919197 \\
\hline 2002 & 0.41111295 & 3.332602141 \\
\hline 2003 & 0.322900204 & 3.265918713 \\
\hline 2004 & 0.287672004 & 2.892441315 \\
\hline 2005 & 0.301021576 & 3.029439926 \\
\hline 2006 & 0.271841078 & 2.846361583 \\
\hline 2007 & 0.391077101 & 2.700526 \\
\hline 2008 & 0.384131063 & 3.229753 \\
\hline 2009 & 0.263445897 & 3.457721 \\
\hline 2010 & 0.351667591 & 2.880979 \\
\hline 2011 & 0.335260259 & 2.790658 \\
\hline
\end{tabular}

Where:

TMICP = Total Motor Insurance Claims Settlement

IP $\quad=\quad$ Insurance Penetration

The above table shows the data for total claims settlement of non-life insurance business within the period 1994-2011. The total motor insurance claims settlement as seen in table 1 above, stood at the rate of $0.46 \%$ in 1994, it declined to $0.37 \%$ in 1995 and later increased to $0.43 \%$ in 1996. In 1997 it stood at $0.46 \%$ and later decreased to $0.42 \%$ in year 1998 . In 2001 it stood at $0.37 \%$, diminished to $0.41 \%, 0.32 \%, 0.30 \%$ and $0.27 \%$ in years 2002 , it increased to $0.39 \%$ but fell $0.38 \%, 0.35 \%$ and $0.33 \%$ in years 2008,2010 and 2011 respectively.

In 1994, insurance penetration amounted to $8.3 \%$, which later decreased to $5 \%$ and $4 \%$ in 1995 and 1996 respectively. In 1997, it improved to $4 \%$ and fell back to $3.8 \%$ and $2.7 \%$ in 1998 and 1999 accordingly. The insurance penetration stood at $3.2 \%$ and $2.8 \%$ in years 2002 , 2003 and 2004 accordingly. In 2008 it was $3.2 \%$, it increased to $3.4 \%$ in 2009 but dropped to $2.8 \%$ and $2.7 \%$ in 2010 and 2011 respectively. 


\begin{tabular}{lcc}
\hline Descriptive Statistics & & \\
& IP & TMICS \\
Mean & 3.597940 & 0.360184 \\
Median & 3.266270 & 0.362609 \\
Maximum & 8.322877 & 0.465568 \\
Minimum & 2.700526 & 0.263446 \\
Std. Dev. & 1.310198 & 0.062922 \\
Skewness & 2.832794 & 1.886741 \\
Kurtosis & 10.68022 & 1.886741 \\
Jarque-Bera & 68.31350 & 0.979027 \\
Probability & 0.000000 & 0.612925 \\
Sum & 64.76292 & 6.483312 \\
Sum Sq. Dev. & 29.18252 & 0.067305 \\
Observations & 18 & 18
\end{tabular}

Source: Author's Compilation from E-views 9, 2018

The study conducted the descriptive statistics of the relevant variables involved.

Test of Hypothesis

Step 1:Restatement of the Hypothesis in the null and alternate form.

$\mathrm{H}_{0}$ : Total motor insurance claims settlement does not have a positive effect on Insurance penetration in Nigeria.

$\mathrm{H}_{1}$ : Total motor insurance claims settlement has positive effect on Insurance penetration in Nigeria.

Step 2: $\quad$ Statement of decision criterion

Accept $\mathrm{H}_{0}$ if the sign of the coefficient is negative.

Otherwise, reject $\mathrm{H}_{0}$ and accept $\mathrm{H}_{1}$ accordingly.

Step 3: $\quad$ Presentation of test result

Table 2: Regression Analysis for Total Fire Insurance Claims Settlement

Dependent Variable: IP

Method: Least Squares

Date: 07/17/18 Time: 22:03

Sample: 19942011

Included observations: 18

\begin{tabular}{lcccc}
\hline \multicolumn{1}{c}{ Variable } & $\mathrm{t}$ Std. Errort-Statistic & Prob. \\
\hline \multicolumn{1}{c}{ C } & -0.446938 & 1.601534 & -0.279069 & 0.7838 \\
\multicolumn{1}{c}{ TMICS } & 11.23003 & 4.383706 & 2.561767 & 0.0209 \\
\hline \hline & 0.290863 & Mean dependent Var & 3.597940 \\
R-squared & 0.246542 & S.D. dependent var & 1.310198 \\
Adjusted R-squared & 1.137277 & Akaike info criterion & 3.199590 \\
S.E of regression & 20.69439 & Schwarz criterion & 3.298520 \\
Sum square resid & -29.88301 & Hannan-Quinn Criter. 3.213231 \\
Log likelihood & 0.011860 & Durbin-Watson stat & 0.936615 \\
F-statistics & 0.020900 & & \\
Prob(F-statistic) & & & \\
\hline \hline
\end{tabular}

Source: Author's E-view 9.0 Output, 2018 
Where:

$\mathrm{C}$

TFICS

IP

$=$

$=$

$=$
Coefficient

Total Motor Insurance Claims Settlement

Insurance Penetration

From the above regression analysis, the $\mathrm{R}^{2}$ is 0.290863 and shows that changes in the dependent variable are explained by the independent variables by $0.29 \%$; also the adjusted $\mathrm{R}^{2}$ which is 0.246542 shows that $2.4 \%$ variation of insurance penetration in Nigeria is caused by total motor insurance claims. The probability of F-statistics which is $0.02>0.05$ shows that the model is insignificant therefore make the model fit.

\section{Step 4: Decision}

Given the decision criteria to accept $\mathrm{H} 0$ if the sign of the coefficient is negative the t-statistics is $<2$ and the probability of the t-statistics is $>0.05$. Table 2 shows the sign of the coefficient of total motor insurance claims settlement is positive at 11.23003. Given the positive sign of the coefficient, we accept the alternate hypothesis $\left(\mathrm{H}_{1}\right)$, and conclude that total motor insurance claims settlement has a positive effect on Insurance penetration in Nigeria.

\section{Summary of Findings}

The summary of findings of this study includes;

i. That total motor insurance claims settlement has a positive effect on insurance penetration in Nigeria.

\section{Conclusion}

Based on the findings, the study concludes that total motor insurance claims settlement have effect on insurance penetration in Nigeria.

\section{Recommendation}

This study recommends that for the safety of injured third parties and damage to property caused by motor accident, insurance should improve their use of modern day technology in facilitating motor insurance claims settlement.

\section{References}

1. Agu K.O.C. (1999). Insurance claims in Nigeria. Enugu; Glanic Ventures press.

2. Gallagher, B. (2012). Catastrophic claims management. Australia, Bassett Services Pty Limited.

3. Kapoor, A.(2008). Strategic Perspectives Off-shoring Claims; The view within the insurance Industry. (Master dissertation), Nottingham University Business School.

4. Marquis, C. (2011). Importance of claims management in insurance sector. Retrieved from www.ehow.com/

5. Oyetayo Y.A (2006): Towards Effective Risk Management in the Insurance industry: A Review of the Nigeria situation, Journal of Chartered Insurance Institute of Nigeria $7(14)$.

6. Peverett, E. (1993). Fire Insurance Laws and Claims. London: Chartered Institute of Loss Adjusters.

7. Rejda, G.E. (2008). Principles of Risk Management and Insurance. 10th ed. New York, Pearson Education. 